\title{
The Impact of Zinc Supplementation on Oxidative Stress and Inflammatory Biomarkers in Opioid Addicts-Withdrawal Syndrome: A Randomized, Double-Blind, Placebo-Controlled Trial
}

\section{Amir Keshavarzi}

Hamadan University of Medical Sciences

Ali Hassanalizade

Hamadan University of Medical Sciences

Akram Ranjbar

Hamadan University of Medical Sciences

Ali Ghaleiha

Hamadan University of Medical Sciences

Seyed Yaser Vafaei

Hamadan University of Medical Sciences

\section{Sara Rezaei}

Hamadan University of Medical Sciences

Shiva Amini

Hamadan University of Medical Sciences

Mohammad Faryadras

Hamadan University of Medical Sciences

Heresh Moridi

Hamadan University of Medical Sciences

\section{Fatemeh Ghaffari}

Hamadan University of Medical Sciences

Sara Ataei ( $\nabla$ dr_sa7142@yahoo.com)

Hamadan University of Medical Sciences https://orcid.org/0000-0002-1211-8132

\section{Research}

Keywords: Oxidative stress, Substance withdrawal syndrome, Zinc supplementation

Posted Date: October 5th, 2021

DOl: https://doi.org/10.21203/rs.3.rs-898468/v1 
License: (a) (i) This work is licensed under a Creative Commons Attribution 4.0 International License. Read Full License 


\section{Abstract \\ Background}

Opioid withdrawal can induce oxidative stress in opioid addicts. This interventional study aimed to investigate the effect of zinc supplementation on the oxidative profile of patients with an opioid withdrawal syndrome.

\section{Methods}

In the current study, 40 patients aged 18 to 65 years with opioid withdrawal syndrome were randomly assigned to intervention and control groups, each with 20 subjects. In addition to standard treatment, the intervention group received $30 \mathrm{mg}$ of zinc daily, while the control group was given a placebo for one month. They were evaluated using Beck Depression Inventory (BDI), Clinical Opiate Withdrawal Scale (COWS), and Young Mania Rating Scale (YMRS) for withdrawal symptoms. Moreover, other parameters included catalase (CAT), superoxide dismutase (SOD), and glutathione peroxidase (GPX) and levels of total antioxidant capacity (TAC), total thiol groups (TTG), tumor necrosis factor- $a(T N F-a)$, and malondialdehyde (MDA).

\section{Results}

The rate of withdrawal symptoms (COWS) was statistically significantly lower in the treated group in comparison to the control group $(P<0.05)$. In the treatment group, the levels of TAC, CAT, SOD, and GPx increased significantly compared to the control group $(P<0.05)$. In the treatment group compared to the control group, there was a statistically significant decrease in hs-CRP, MDA, and TNFa $(P<0.05)$.

\section{Conclusions}

The results revealed that zinc supplementation could effectively reduce withdrawal symptoms by increasing antioxidant activity and reducing the lipid peroxidation index.

\section{Background}

Addiction drugs, especially opioids, is a common problem with an increasing prevalence around the world [1]. Since the beginning of 1990, the world's annual consumption of opiates has increased from an average of 200 tons of morphine (equivalent to 236.7 tons of morphine in 1993( [2]. In this regard, Iran's strategic location and its proximity to Afghanistan and Pakistan, which are the major source of opium globally, have led to a high prevalence of opioid use in this country. Although no government has been as active in fighting against drug trafficking as Iran, the number of addicts in Iran has increased in recent decades [3]. Long-term use of opioids is accompanied by dependency problems such that after a while, neurons are insensitive to natural agonists produced in the body [4]. This insensitivity causes a higher dose of these substances to be required for the normal functioning of the body neurons, which sometimes causes overdose in addicted 
people [5]. Opioid withdrawal syndrome is referred to a series of physiological and behavioral changes associated with morphine-like motivational stimulation that occurs in a person [6]. This syndrome is accompanied by symptoms such as diarrhea, seizures, muscle aches, severe nervous irritability, and gastrointestinal disorders that make the withdrawal process difficult [7].

Oxidative stress is described as an increase in the generation of free radicals or a decrease in antioxidant defense agents [8]. Antioxidants that protect the body against oxidative agents are of two types: 1) in the form of enzymes that are not consumed during the reaction and 2) substances such as complexes with catalytic metal elements that are consumed during the reactions. Superoxide dismutase (SOD), Glutathione peroxidase (GPx), and Catalase (CAT) are among the essential antioxidant enzymes [9]. Previous data indicate that oxidative stress contributes to the development of the withdrawal process. In this respect, antioxidants also play a role in reducing oxidative stress as they result in some withdrawal symptoms [10, 11]. Studies have demonstrated that oxidative stress disrupts the immune system and also cause inflammation in the body $[12,13]$. Joseph Wybran Laid, for the first time, stated that opioids regulate and interfere with the immune system by occupying opioid receptors in immune cells [14]. High-sensitivity Creactive protein (hs-CRP) is another protein that is considered a suitable and sensitive marker for measuring inflammation. This protein, which is produced in the liver, increases during inflammatory diseases [15].

Zinc is one of the strongest antioxidants and essential compounds of many antioxidant enzymes, including SOD, and a cofactor of many important enzymes in glucose and lipid metabolism [16]. Some studies represented that zinc may reduce lipid peroxidation while improving the antioxidant status of people by its antioxidant effect. Also, it has been reported that zinc reduces the expression of many inflammatory factors, including tumor necrosis factor-a (TNF-a) and interleukin (IL-1 $\beta$ ) by affecting the level of gene expression. Eventually, it increases the expression of anti-inflammatory factors such as IL-10 [17]. Zinc deficiency, leading to an increase in inflammatory cytokines, including TNF-a. It also declines these inflammatory cytokines in the body [18]. Given the role of oxidative stress during opioid withdrawal and considering that insufficient studies were conducted in this field, the present clinical trial study was an attempt to examine the effect of zinc supplementation during opioid withdrawal syndrome on the antioxidants, oxidation, and associated symptoms in these patients.

\section{Methods}

\subsection{Study design}

This prospective clinical trial study was performed from July 22 of 2020 to November 20 of 2020 at Farshchian Hospital affiliated with Hamadan University of Medical Sciences in the west of Iran. Informed consent was obtained from the participants to participate in this study. In addition, the study protocol was confirmed by the Ethics Committee of Hamadan University of Medical Sciences and registered in the IRCT with a code of IRCT20190811044513N1.

The study's inclusion criteria were opioid use for one year or more, need for hospitalization for withdrawal syndrome based on psychiatrist's diagnosis, absence of acute and chronic inflammatory diseases and any 
other acute or chronic infections, and having no AIDS, hepatitis, and diabetes. Exclusion criteria of the study were re-use of substances during the study, the use of drugs that affect inflammation and oxidative stress, and suicide ideation during the past year. The inclusion and exclusion of the patients are presented in Fig. 1.

At the beginning of the study, a comprehensive interview was performed, followed by collecting demographic information, including underlying disease, history of opioid withdrawal, duration of addiction, and body mass index (BMI). Beck Depression Inventory (BDI) questionnaire was completed for patients with depressed moods. The reliability and validity of this instrument was previously approved by Lee et al [19].

For patients with high mood, the Young Mania Rating Scale (YMRS) was completed [20]. Also, withdrawal symptoms were estimated using the Clinical Opiate Withdrawal Scale (COWS), which its validity and reliability had been previously confirmed [21]. At the beginning and end of the study, these questionnaires were completed by a psychiatrist. Patients in the intervention group received $30 \mathrm{mg}$ of zinc gluconate tablets daily for one month. The intervention group was advised to take zinc supplementation with a full stomach to reduce its side effects. A placebo (in an identical shape and color as the main drug) prepared by the School of Pharmacy was used in the placebo group. Randomization was done through the block randomization method with quadruple blocks. The details of this method are presented by Prasad et al [22]. In this study, the drug was not distinguishable from placebo, and the patients were blinded for the study. Moreover, physicians and statistical analysts were not aware of the allocation of groups due to coding the drug and placebo. Accordingly, the study was performed in a triple-blinded form.

\subsection{Blood sampling and biochemical measurements}

SOD, TAC, GPx, hs-CRP, MDA, TTG, and TNF-a indices were measured by taking a 5-cc sample of fasting intravenous blood at the beginning and end of the study between 7 and 9 a.m. Next, the blood sample was taken from patients, and serum was separated from blood by centrifuging it at 25,000 rpm for $10 \mathrm{~min}$ (Iran, Centrifuge). Finally, it was stored at $-70^{\circ} \mathrm{C}$.. ELISA method (Kiazist Company-Iran) was used to evaluate activities of several variables, including GPx, CAT, and SOD and levels of total antioxidant capacity (TAC), TNF-a, and hs-CRP in the serum, and malondialdehyde (MDA).

\subsection{Sample volume and statistical analysis}

Based on the study performed by Prasad et al., the sample size was determined to be 20 individuals in each study group, with statistical power and confidence level of $90 \%$ and $95 \%$, respectively. ${ }^{18}$ Also, the significance level was considered less than $5 \%$. Data were expressed using descriptive statistics of the mean and standard deviation (Mean \pm SD) and the ratio and percentage for quantitative and qualitative variables, respectively. The Chi-square test was employed to compare qualitative variables. Finally, independent and paired t-tests were applied since the Kolmogorov-Smirnov test represented that data follow a normal distribution.

\section{Results}

In general, all 40 patients in the zinc $(n=20)$ and placebo $(n=20)$ groups completed the intended 30-day clinical trial. The results demonstrated allowable agreement with the intervention, and no adverse effects or 
symptoms were reported regarding zinc supplementation. Table 1 provides the demographic and clinical features of the subjects.

Table 1

Patients' general characteristics in two group

\begin{tabular}{|c|c|c|c|}
\hline Variables & $\begin{array}{l}\text { Zinc Group } \\
(n=20)\end{array}$ & $\begin{array}{l}\text { Placebo Group } \\
(n=20)\end{array}$ & $P$-value \\
\hline \multicolumn{4}{|l|}{ Gender, n (\%) } \\
\hline Male & 18(90.0) & $19(95.0)$ & 0.458 * \\
\hline Female & $2(10.0)$ & $1(5.0)$ & \\
\hline \multicolumn{4}{|l|}{ Underlying disease $\mathrm{n}(\%)$} \\
\hline Yes & $16(80.0)$ & 18(90.0) & 0.376 * \\
\hline No & $4(20.0)$ & $2(10.0)$ & \\
\hline \multicolumn{4}{|l|}{ Smoking, n (\%) } \\
\hline Yes & 18(90.0) & 19(95.0) & 0.548 * \\
\hline No & $2(10.0)$ & $1(5.1)$ & \\
\hline \multicolumn{4}{|l|}{ Previous withdrawal, n (\%) } \\
\hline Yes & $15(75.0)$ & $14(70.0)$ & 0.723 * \\
\hline No & $5(25.0)$ & $6(30.0)$ & \\
\hline Age (yr.), $M \pm S D$ & $32.45 \pm 6.41$ & $31.85 \pm 8.82$ & $0.807+$ \\
\hline Duration addiction (yr.) $\mathrm{M} \pm \mathrm{SD}$ & $5.12 \pm 3.18$ & $6.55 \pm 3.73$ & $0.202+$ \\
\hline $\mathrm{BMI} \square \mathrm{kg} / \mathrm{m}^{\wedge} 2 . \mathrm{M} \pm \mathrm{SD}$ & $22.77 \pm 2.01$ & $23.24 \pm 1.85$ & $0.451 \dagger$ \\
\hline
\end{tabular}

The results showed no significant differences between the groups regarding baseline values related to demographic features or within subjects' addiction measures $(P>0.05)$.

The data related to $\mathrm{BDI}, \mathrm{YMAS}$, and COWS measurements before and following the intervention are presented in Table 2. At the beginning of the study, no significant differences were observed between the zinc and placebo groups in terms of BDI, YMAS, and COWS measurements $(P>0.05)$. 
Table 2

Comparison of the effect of zinc and placebo on withdrawal symptoms, depression, and euphoria

\begin{tabular}{|c|c|c|c|c|}
\hline Parameter & Time & $\begin{array}{l}\text { zinc group } \\
(n=20)\end{array}$ & $\begin{array}{l}\text { Placebo group } \\
(n=20)\end{array}$ & $\begin{array}{l}\text { MD(95\%Cl), P- } \\
\text { value }^{\mathrm{a}}\end{array}$ \\
\hline \multirow[t]{2}{*}{ YMRS } & Onset & $28.55 \pm 2.50$ & $28.35 \pm 1.46$ & $.0 .2(1.11,1.51) 0.750$ \\
\hline & End & $21.20 \pm 2.01$ & $22.15 \pm 1.81$ & $\begin{array}{l}-0.95(-2.17, .27) \\
0.125\end{array}$ \\
\hline $\mathrm{MD}(95 \% \mathrm{Cl}), \mathrm{P}-$ value $^{\mathrm{b}}$ & & $\begin{array}{l}-7.35(-8.83,-5.86)< \\
0.001\end{array}$ & $\begin{array}{l}-6.20(-7.15,-5.24)< \\
0.001\end{array}$ & \\
\hline \multirow[t]{2}{*}{$\begin{array}{l}\text { Beck Depression } \\
\text { Inventory }\end{array}$} & Onset & $25.70 \pm 1.97$ & $25.80 \pm 1.60$ & $\begin{array}{l}-0.1(-1.25,1.05) \\
0.861\end{array}$ \\
\hline & End & $22.60 \pm 2.11$ & $23.25 \pm 1.74$ & $\begin{array}{l}-0.65(-1.88,0.58) \\
0.295\end{array}$ \\
\hline $\mathrm{MD}(95 \% \mathrm{Cl}), \mathrm{P}$-value & & $\begin{array}{l}-3.1(-3.55,-2.64)< \\
0.001\end{array}$ & $\begin{array}{l}-2.55(-2.99,-2.10)< \\
0.001\end{array}$ & \\
\hline \multirow[t]{2}{*}{ cows } & Onset & $26.45 \pm 4.71$ & $26.55 \pm 2.83$ & $\begin{array}{l}-0.1(-2.59,2.39) \\
0.935\end{array}$ \\
\hline & End & $10.85 \pm 0.98$ & $14.00 \pm 1.21$ & $\begin{array}{l}-3.15(-3.85,-2.44)< \\
0.001\end{array}$ \\
\hline MD(95\%Cl), P value & & $\begin{array}{l}-15.6(-17.74,-13.45)< \\
0.001\end{array}$ & $\begin{array}{l}-12.55(-13.76,-11.33)< \\
0.001\end{array}$ & \\
\hline $\begin{array}{l}\text { Note. Values are indic } \\
\text { group); b: Paired sam } \\
\text { Withdrawal Scale }\end{array}$ & $\begin{array}{l}\text { ed as th } \\
\text { t-test }\end{array}$ & $\begin{array}{l}\text { mean } \pm \text { standard devia } \\
\text { ithin-group); Yang: You }\end{array}$ & $\begin{array}{l}\text { on; a: Independent samp } \\
\text { Mania Rating Scale; CC }\end{array}$ & $\begin{array}{l}\text { t-test (between- } \\
\text { VS: Clinical Opiate }\end{array}$ \\
\hline
\end{tabular}

After the treatment, the COWS scale decreased in the intervention group compared to the control group, indicating a significant reduction in the severity of symptoms in this group $(P \leq 0.001)$. At the end of the study, all three scales (i.e., COWS, YMAS, and BDI) showed a significant decrease in both groups $(P \leq 0.001)$ compared to the beginning of the study.

Table 3 summarizes results related to the SOD, TAC, GPx, hs-CRP, MDA, and TTG concentrations before and after the intervention. At the beginning of the study, there were no statistically significant differences between the zinc and placebo groups in terms of the mentioned parameters $(P>0.05)$. 
Table 3

Serum CAT, TAC, GPx, SOD, MDA, TNF- $a$, TTG, and hs-CRP of withdrawal patients at the baseline and after 30 day of zinc intervention

\begin{tabular}{|c|c|c|c|c|}
\hline Parameter & Time & $\begin{array}{l}\text { zinc group } \\
(n=20)\end{array}$ & $\begin{array}{l}\text { Placebo group } \\
(n=20)\end{array}$ & $M D(95 \% C l), P$ value ${ }^{a}$ \\
\hline \multirow[t]{2}{*}{$\mathrm{CAT}(\mu \mathrm{mol} / \mathrm{mg})$} & Onset & $32.55 \pm 9.87$ & $36.2 \pm 10.92$ & $-3.65(-10.31,-.01) 0.274$ \\
\hline & End & $41.15 \pm 15.70$ & $30.20 \pm 12.99$ & $10.95(1.72,20.17) 0.021$ \\
\hline \multicolumn{2}{|c|}{$\mathrm{MD}(95 \% \mathrm{Cl}), \mathrm{P}$ value ${ }^{\mathrm{b}}$} & $8.6(16.17,1.02) 0.028$ & $-6.0(-12.70,0.70) 0.076$ & \\
\hline \multirow[t]{2}{*}{$\mathrm{TAC}(\mu \mathrm{mol} / \mathrm{mg})$} & Onset & $1.87 \pm .26$ & $1.91 \pm .31$ & $-0.03(-0.22,0.14) 0.8681$ \\
\hline & End & $2.03 \pm .28$ & $1.81 \pm .23$ & $0.22(0.05,0.39) 0.009$ \\
\hline \multicolumn{2}{|c|}{ MD(95\%Cl), P value ${ }^{b}$} & $0.16(0.00,0.32) 0.048$ & $-0.1(-0.21,0.01) 0.072$ & \\
\hline \multirow{2}{*}{$\begin{array}{l}\text { GPx } \\
(\mu \mathrm{mol} / \mathrm{mg})\end{array}$} & Onset & $24.19 \pm 6.76$ & $26.80 \pm 7.78$ & $-2.60(-7.27,2.06) 0.265$ \\
\hline & End & $30.86 \pm 10.67$ & $23.98 \pm 10.03$ & $6.88(0.24,13.51) 0.042$ \\
\hline \multicolumn{2}{|c|}{ MD(95\%Cl), P value ${ }^{b}$} & $6.66(1.33,11.90) 0.017$ & $-2.82(-8.39,2.75) 0.303$ & \\
\hline \multirow{2}{*}{$\begin{array}{l}\text { SOD } \\
(\mu \mathrm{mol} / \mathrm{mg})\end{array}$} & Onset & $73.70 \pm 11.80$ & $75.05 \pm 17.56$ & $-1.35(-10.92,8.22) 0.776$ \\
\hline & End & $80.95 \pm 10.40$ & $70.35 \pm 17.19$ & $10.6(1.49,19.70) 0.023$ \\
\hline \multicolumn{2}{|c|}{$\mathrm{MD}(95 \% \mathrm{Cl}), \mathrm{P}$ value } & $7.25(0.65,13.84) 0.033$ & $-4.7(-13.21,3.81) 0.262$ & \\
\hline \multirow[t]{2}{*}{ MDA } & Onset & $3.23 \pm 2.06$ & $2.78 \pm 1.87$ & $0.44(-0.82,1.70) 0.482$ \\
\hline & End & $1.88 \pm .70$ & $3.05 \pm 1.87$ & $-1.16(-2.07,-0.26) 0.013$ \\
\hline \multicolumn{2}{|c|}{ MD(95\%Cl), P value ${ }^{b}$} & $-1.34(-2.34,-0.35) 0.010$ & $0.26(-0.97,1.50) 0.660$ & \\
\hline \multirow[t]{2}{*}{ TNF-a } & Onset & $54.30 \pm 21.18$ & $50.46 \pm 23.92$ & $3.83(-10.62,18.3) 0.954$ \\
\hline & End & $40.15 \pm 23.73$ & $55.66 \pm 19.07$ & $-15.50(-29.28,-1.72) 0.028$ \\
\hline \multicolumn{2}{|c|}{ MD(95\%Cl), P value ${ }^{b}$} & $\begin{array}{l}-14.14(-27.14,-1.14) \\
0.034\end{array}$ & $5.19(-5.54,15.94) 0.323$ & \\
\hline \multirow[t]{2}{*}{ TTG } & Onset & $.03 \pm .02$ & $.03 \pm .03$ & $0.00(-0.01,0.02) 0.540$ \\
\hline & End & $.03 \pm .02$ & $.02 \pm .01$ & $0.01(-0.00,0.02) 0.132$ \\
\hline \multicolumn{2}{|c|}{ MD(95\%Cl), P value ${ }^{b}$} & $-0.05(-0.01,0.00) 0.464$ & $-0.00(-0.02,0.00) 0.278$ & \\
\hline hs-CRP & Onset & $1.70 \pm .52$ & $1.75 \pm .55$ & $-0.05(-0.40,0.30) 0.799$ \\
\hline
\end{tabular}

Note. Values are indicated as the mean \pm standard deviation; a: $P$ value is reported based on the analysis of independent sample t-test; TAC: Total antioxidant capacity; SOD: Superoxide dismutase; GPx:

Glutathione peroxidase; MDA: Malondialdehyde; hs-CRP: High-sensitivity C-reactive protein; TNF-a: Tumor necrosis factor-a; TTG: Thiol group, b: P value is reported based on the analysis of paired sample t-test 


\begin{tabular}{|c|c|c|c|}
\hline Parameter & $\begin{array}{l}\text { zinc group } \\
(n=20)\end{array}$ & $\begin{array}{l}\text { Placebo group } \\
(n=20)\end{array}$ & $\mathrm{MD}(95 \% \mathrm{Cl}), \mathrm{P}$ value ${ }^{\mathrm{a}}$ \\
\hline End & $.85 \pm .48$ & $1.55 \pm .60$ & $-0.7(-1.05,-0.34)<0.001$ \\
\hline $\mathrm{MD}(95 \% \mathrm{Cl}), \mathrm{P}$ value ${ }^{\mathrm{b}}$ & $\begin{array}{l}-0.85(-1.19,-0.50)< \\
0.001\end{array}$ & $-0.2(-0.488,0.08) 0.165$ & \\
\hline \multicolumn{4}{|c|}{$\begin{array}{l}\text { Note. Values are indicated as the mean } \pm \text { standard deviation; a: P value is reported based on the analysis } \\
\text { of independent sample t-test; TAC: Total antioxidant capacity; SOD: Superoxide dismutase; GPx: } \\
\text { Glutathione peroxidase; MDA: Malondialdehyde; hs-CRP: High-sensitivity C-reactive protein; TNF-a: Tumol } \\
\text { necrosis factor-a; TTG: Thiol group, b: P value is reported based on the analysis of paired sample t-test }\end{array}$} \\
\hline
\end{tabular}

However, the results represented an increase in the CAT level in the intervention group after one month of consumption compared with the control group $(P=0.021)$ and pre-intervention $(P=0.028)$. The results also showed an increase in the TAC level in the intervention group compared to the control group $(P=0.009)$ and pre-intervention $(P=0.048)$. The findings further revealed that the GPx level increased in the intervention group compared to the control group $(P=0.042)$ and pre-intervention $(P=0.017)$. Besides, an increase was found in the SOD level in the intervention group compared to the control group $(P=0.023)$ and preintervention $(P=0.033)$. In contrast, the results demonstrated a decrease in the level of MDA in the intervention group compared to the control group $(P=0.013)$ and pre-intervention $(P=0.010)$. In addition, TNF-a level declined in the intervention group compared to the control group $(P=0.028)$ and pre-intervention $(P=0.034)$. Furthermore, hs-CRP level did not increase in the intervention group compared to the control group $(P \leq 0.001)$ and pre-intervention $(P \leq 0.001)$. Finally, the TTG level in the two groups showed no significant changes.

\section{Discussion}

Overall, the findings of the current clinical trial study revealed that zinc supplementation could lower inflammation status and oxidative stress while improving withdrawal symptoms in opioid addicts. Most of the studied patients were male regarding the higher prevalence of opioids in males and the cultural and social conditions, wherein males are more likely to withdraw. The results showed that the studied patients did not have a high underlying disease prevalence, probably due to patients' low BMI and low mean age. Our study showed that taking $30 \mathrm{mg}$ of zinc gluconate supplementation daily for one month and routine treatment in patients with opioid withdrawal syndrome could effectively reduce oxidative stress (e.g., an increase in TAC) and a reduction in pro-inflammatory cytokine and lipid peroxidation index.

Zinc, the second most abundant element in the body after iron, exerts a wide variety of roles, such as contributing to the body as an antioxidant [23]. It also has an essential role in the structure and function of antioxidant enzymes and biological membranes. More than $15 \%$ of people worldwide have zinc deficiency, which is more common in people addicted to opioids [24]. Zinc deficiency in addicted people is highly associated with enhanced urinary excretion. Malnutrition is another cause of zinc deficiency in addicted people [25]. Few studies have investigated the effect of zinc supplementation in patients suffering from opioid withdrawal syndrome. Despite most of the other studies in this regard that are on animals, the present 
study is on humans. It has been evidenced that oral supplementation can reduce the symptoms of opioid dependence [26]. Results of an animal study performed by Ranjbar et al. demonstrated that zinc sulfate supplementation improves oxidative and reduces MDA and DNA damage compared to the control group. Based on the results of the Ranjbar study, the antioxidant enzyme activity in the liver of rats significantly increased in the zinc-treated group except for the TTG compared to the control group. The mentioned results are consistent with those mentioned in our study. Investigating patients is another strength of the present study. In a survey on morphine-dependent rats, Ciubotariu et al. showed that the use of zinc sulfate is effective in reducing opioid dependence [27]. In another study by Larson et al. (2000) on mice, it was observed that zinc reduced pain in morphine-dependent mice [28]. Xu et al. concluded that antioxidant administration could inhibit oxidative stress and reduce the withdrawal symptoms of heroin [10]. Ba Cemek et al. observed an increase in the level of lipid peroxidation while that of the antioxidants decreased during the withdrawal syndrome. Moreover, the administration of antioxidants such as selenium and vitamin $\mathrm{E}$ reduces lipid peroxidation [29]. Pan et al. showed that oxidative stress increases during withdrawal syndrome and t antioxidant administration could inhibit oxidative stress and reduce withdrawal syndrome [30]. In the present study, symptoms of depression, euphoria, and withdrawal showed more improvement in the intervention group. Baker et al. also confirmed that the administration of antioxidants could lower oxidative stress and the severity of withdrawal symptoms [11]. Elsewhere, Klotz et al. showed the defensive and antioxidant effect of zinc [31].

Prasad et al. observed that zinc deficiency increases oxidative stress and inflammatory factors. It was also reported that the administration of food supplementations or zinc declines two mentioned factors, which conforms with the present study results [18]. According to the results of another study by Prasad et al., in people taking zinc supplementation, the production of oxidative stress markers and the incidence of infection decreased significantly [22]. In line with the present study, a recent study performed in Egypt by Saad-Hussein et al. showed that zinc supplementation in pesticide sprayers was associated with increased antioxidant capacity and decreased MDA [16]. The main mechanism of action zinc in reducing the symptoms of withdrawal syndrome is not yet fully understood. Zinc may reduce the symptoms in these patients by binding to opioid agonist receptors $\mu$ [32]. Therefore, generalizing the results of animal studies on a human should be done cautiously because zinc is usually injected into animals while it is used orally in humans. Elsewhere, it was reported that other antioxidant compounds decrease patients' symptoms and faster recovery during opioid withdrawal. For instance, Mostaghinejad et al. concluded that curcumin might contribute to reducing the withdrawal syndrome in rats in a dose-dependent manner [33]. Salahshour et al. showed that crocin as an antioxidant compound in saffron could effectively produce free radicals caused by morphine consumption [34]. Additionally, Hasani et al. demonstrated the anti-oxidative impact of zinc sulfate on liver oxidative stress in morphine-withdrawal syndrome in rats [26].

The current study results indicated that TNF-a led to a significant reduction in the intervention group after receiving zinc supplementation. Some other studies reported that inhibitors of this parameter have a major role in the immune system in the development of withdrawal syndrome. It has also been shown that inhibitors of this inflammatory factor mainly contribute to decreasing the symptoms of withdrawal syndrome [35]. Consistent with the present study, it was reported that zinc supplementation increased the immune system and reduced inflammation [36]. Opioid withdrawal also inhibits the immune system, 
including inhibiting the proliferation of B-lymphocytes, suppressing the production of interleukins 2 , 4, and 12 from T lymphocytes, and reducing the activity of killer cells [37]. Withdrawal of opioids inhibits interleukin 12 production, increasing the infection risk [38].

In the present study, the patients in the intervention group were recommended to take zinc along with food to prevent gastrointestinal side effects. No serious side effect was reported for zinc to discourage patients from zinc supplementation. Taking zinc, especially orally, is associated with side effects such as nausea, vomiting, epigastric pain, lethargy, and extreme fatigue that may occur if consumed more than the allowable level [1]. Like other epidemiological studies, the present study has some limitations. One limitation is relatively small sample sizes. Another limitation of this study was the lack of measuring serum zinc levels in patients and ensuring correct consumption in the intervention group.

\section{Conclusion}

Considering the current study's findings, the oral consumption of zinc supplementation during opioid withdrawal syndrome may be a good option in treating these patients regarding its safety and beneficial effects in increasing antioxidant effects and reducing withdrawal symptoms. However, conducting studies with larger sample sizes and long-term follow-ups is suggested to validate the results of this research.

\section{Abbreviations}

Beck Depression Inventory (BDI)

Clinical Opiate Withdrawal Scale (COWS)

Young Mania Rating Scale (YMRS)

Catalase (CAT)

Superoxide dismutase (SOD)

Glutathione peroxidase (GPx)

Total antioxidant capacity (TAC)

Total thiol groups (TTG)

Tumor necrosis factor-a (TNF-a)

\section{Declarations}

\section{Data Availability}

The authors confirm that the data supporting the findings of this study are available within the article.

\section{Acknowledgments}


We would like to gratitude the participants in this study for their collaboration and Hamadan University of Medical Sciences

\section{Conflict of Interests}

The authors declare to have no conflict of interest.

\section{Consent to publication}

Not applicable.

\section{Author contributions}

Conceptualization; Amir Keshavarzi, Data curation; Ali Hassanalizade, Formal analysis; Mohammad Faryadras, Investigation; Akram Ranjbar, Project administration; Ali Ghaleiha, Supervision; Sara Ataei, Writing of original draft; Sara Rezaei and Shiva Amini, Review \& editing; Heresh Moridi, Resources; Seyed Yaser Vafaei, Analysis of Biomarkers tests results; Fatemeh Ghaffari. All authors revised and approved the final manuscript.

\section{Ethics approval and consent to participate}

This study was approved by the Human Research Ethics Committee of Hamadan University of Medical Sciences under the ethics approval code of IR.UMSHA.REC.1398.306. Written informed consent was obtained from all participants included in the study.

Research Funding: This study was supported by a grant from the Vice-chancellor of the Research and Technology of Hamadan University of Medical Sciences (grant number: 9808216021).

\section{References}

1. Shetty PA, Dharia HV, Goodman. \& Gilman's the Pharmacological Basis of Therapeutics 12 th Edition 2011. The Indian Practitioner. 2015;68(7):68-8.

2. Ehsanmanesh M, KARIMI KE. A review of the history and several studies regarding substance abuse in Iran. 2000.

3. Saberi Zafarghandi M. Some of the challenges of mental health and addiction in Iran. Iranian Journal of Psychiatry Clinical Psychology. 2011;17(2):161-157.

4. Højsted J, Sjøgren P. Addiction to opioids in chronic pain patients: a literature review. Eur J Pain. 2007;11(5):490-518. doi:https://doi.org/10.1016/j.ejpain.2006.08.004.

5. Li Sx, Liu Lj, Jiang Wg, et al. Circadian alteration in neurobiology during protracted opiate withdrawal in rats. Journal of neurochemistry. 2010;115(2):353-62. doi:10.1111/j.1471-4159.2010.06941.x.

6. Cui R, Suemaru K, Li B, Kohnomi S, Araki H. Tropisetron attenuates Naloxone-induced place aversion in single-dose morphine-treated rats: role of a7 nicotinic receptors. Eur J Pharmacol. 2009;609(1-3):74-7. doi:https://doi.org/10.1016/j.ejphar.2008.12.051. 
7. Peltz G, Clark D, Lawrence C. Methods and compositions for treating or preventing narcotic withdrawal symptoms. Google Patents; 2016.

8. Predy V, Reilly M, Mantlc O, Peters T. Oxidative damage in liver diseases. JIFCC. 1998;10:16-20.

9. Halliwell B, Gutteridge JM. The antioxidants of human extracellular fluids. Arch Biochem Biophys. 1990;280(1):1-8. doi:https://doi.org/10.1016/0003-9861(90)90510-6.

10. Xu B, Wang Z, Li G, et al. Heroin-administered mice involved in oxidative stress and exogenous antioxidant-alleviated withdrawal syndrome. Basic Clin Pharmacol Toxicol. 2006;99(2):153-61. doi:https://doi.org/10.1111/j.1742-7843.2006.pto_461.x.

11. Bakar NHA, Hashim SN, Mohamad N, et al. Role of oxidative stress in opiate withdrawal and dependence: Exploring the potential use of honey. Journal of Applied Pharmaceutical Science. 2015;5(12):159-61. doi:https://doi.org/10.7324/JAPS.2015.501228.

12. Tai XG, Toyo-oka K, Yamamoto N, et al. Expression of an inducible type of nitric oxide (NO) synthase in the thymus and involvement of NO in deletion of TCR-stimulated double-positive thymocytes. J Immunol. 1997;158(10):4696-703.

13. Ganeshan K, Chawla A. Metabolic regulation of immune responses. Annu Rev Immunol. 2014;32:60934. doi:https://doi.org/10.1146/annurev-immunol-032713-120236.

14. Wybran J, Appelboom T, Famaey JP, Govaerts A. Suggestive evidence for receptors for morphine and methionine-enkephalin on normal human blood T lymphocytes. J Immunol. 1979;123(3):1068-70.

15. Ridker PM. Inflammatory biomarkers and risks of myocardial infarction, stroke, diabetes, and total mortality: implications for longevity. Nutrition reviews. 2007;65(suppl_3):253-9. doi:https://doi.org/10.1111/j.1753-4887.2007.tb00372.x.

16. Saad-Hussein A, Ibrahim KS, Abdalla MS, El-Mezayen HA, Osman NF. Effects of zinc supplementation on oxidant/antioxidant and lipids status of pesticides sprayers. Journal of Complementary Integrative Medicine. 2019;17(1).doi:https://doi.org/10.1515/jcim-2019-0001.

17. Adams ML, Kalicki JM, Meyer ER, Cicero TJ. Inhibition of the morphine withdrawal syndrome by a nitric oxide synthase inhibitor, NG-nitro-L-arginine methyl ester. Life sciences. 1993;52(22):PL245-9. doi:https://doi.org/10.1016/0024-3205(93)90472-F.

18. Prasad AS. Zinc is an antioxidant and anti-inflammatory agent: its role in human health. Frontiers in nutrition. 2014;1:14. doi:https://doi.org/10.3389/fnut.2014.00014.

19. Lee EH, Lee SJ, Hwang ST, Hong SH, Kim JH. Reliability and validity of the Beck Depression Inventory-II among Korean adolescents. Psychiatry investigation. 2017;14(1):30.

doi:https://doi.org/10.4306/pi.2017.14.1.30.

20. Shabani A, Akbari M, Dadashi M. Reliability and validity of the Bipolar Depression Rating Scale on an Iranian sample. ARCHIVES OF IRANIAN MEDICINE. 2010;13(3):217-22.

21. Tompkins DA, Bigelow GE, Harrison JA, Johnson RE, Fudala PJ, Strain EC. Concurrent validation of the Clinical Opiate Withdrawal Scale (COWS) and single-item indices against the Clinical Institute Narcotic Assessment (CINA) opioid withdrawal instrument. Drug Alcohol Depend. 2009;105(1-2):154-9. doi:https://doi.org/10.1016/j.drugalcdep.2009.07.001. 
22. Prasad AS, Beck FW, Bao B, et al. Zinc supplementation decreases incidence of infections in the elderly: effect of zinc on generation of cytokines and oxidative stress. Am J Clin Nutr. 2007;85(3):837-44. doi:https://doi.org/10.1093/ajcn/85.3.837.

23. Fraga CG. Relevance, essentiality and toxicity of trace elements in human health. Mol Aspects Med. 2005;26(4-5):235-44. https://doi.org/10.1016/j.mam.2005.07.013.

24. McCall KA, Huang Cc, Fierke CA. Function and mechanism of zinc metalloenzymes. J Nutr. 2000;130(5):1437S-1446S. doi:https://doi.org/10.1093/jn/130.5.1437S.

25. Ciubotariu D, Ghiciuc CM, Lupușoru CE. Zinc involvement in opioid addiction and analgesia-should zinc supplementation be recommended for opioid-treated persons? Substance abuse treatment, prevention, and policy. 2015;10(1):1-14. doi: https://doi.org/10.1186/s13011-015-0025-2.

26. Hasani S, Ghasemi H, Ranjbar A, et al. Protective effect of zinc sulfate and continuous/interval training on liver oxidative stress in morphine-withdrawal syndrome in rats. Physiology Pharmacology. 2020;24(4). doi:http://dx.doi.org/10.32598/ppj.24.4.10.

27. Ciubotariu D, Ghiciuc CM, Lupușoru RV, Bibire N, Agoroaei L. Lupușoru C.E. Experimental research showing the beneficial effect of oral zinc administration in opioid tolerance. Farmacia. 2015;63:835-9.

28. Larson AA, Kovács KJ, Spartz AK. Intrathecal Zn2 + attenuates morphine antinociception and the development of acute tolerance. European journal of Pharmacology. 2000;407(3):267-72. doi:https://doi.org/10.1016/S0014-2999(00)00715-9.

29. Cemek M, Büyükokuroğlu ME, Hazman Ö, Konuk M, Bulut S, Birdane YO. The roles of melatonin and vitamin $E$ plus selenium in prevention of oxidative stress induced by naloxone-precipitated withdrawal in heroin-addicted rats. Biol Trace Elem Res. 2011;142(1):55-66. doi:https://doi.org/10.1007/s12011-0108744-8.

30. Pan J, Zhang Q, Zhang Y, Ouyang Z, Zheng Q, Zheng R. Oxidative stress in heroin administered mice and natural antioxidants protection. Life sciences. 2005;77(2):183-93. doi:https://doi.org/10.1016/j.lfs.2004.12.025.

31. Klotz LO, Kröncke KD, Buchczyk DP, Sies H. Role of copper, zinc, selenium and tellurium in the cellular defense against oxidative and nitrosative stress. J Nutr. 2003;133(5):1448S-1451S. doi:https://doi.org/10.1093/jn/133.5.1448S.

32. Tejwani G, Hanissian S. Modulation of mu, delta and kappa opioid receptors in rat brain by metal ions and histidine. Neuropharmacology. 1990;29(5):445-52. doi:https://doi.org/10.1016/00283908(90)90166-0.

33. Motaghinejad M, Bangash MY, Hosseini P, Karimian SM, Motaghinejad O. Attenuation of morphine withdrawal syndrome by various dosages of curcumin in comparison with clonidine in mouse: possible mechanism. Iranian journal of medical sciences. Iranian Journal of Medical Sciences. 2015;40(2):125.

34. Salahshoor MR. Protective effect of crocin on liver toxicity induced by morphine. Research in pharmaceutical sciences. 2016;11(2):120.

35. Rehni AK, Bhateja P, Singh TG, Singh N. Nuclear factor-K-B inhibitor modulates the development of opioid dependence in a mouse model of naloxone-induced opioid withdrawal syndrome. Behavioural pharmacology. 2008;19(3):265-9. doi:https://doi.org/10.1097/FBP.0b013e3282febcd9.

Page 14/15 
36. Ebrahimi FA, Foroozanfard F, Aghadavod E, Bahmani F, Asemi Z. The effects of magnesium and zinc cosupplementation on biomarkers of inflammation and oxidative stress, and gene expression related to inflammation in polycystic ovary syndrome: a randomized controlled clinical trial. Biol Trace Elem Res. 2018;184(2):300-7. doi:https://doi.org/10.1007/s12011-017-1198-5.

37. Eisenstein TK, Rahim RT, Feng P, Thingalaya NK, Meissler JJ. Effects of opioid tolerance and withdrawal on the immune system. Journal of Neuroimmune Pharmacology. 2006;1(3):237-49. doi:https://doi.org/10.1007/s11481-006-9019-1.

38. Feng P, Wilson QM, Meissler JJ, Adler MW, Eisenstein TK. Increased sensitivity to Salmonella enterica serovar Typhimurium infection in mice undergoing withdrawal from morphine is associated with suppression of interleukin-12. Infect Immun. 2005;73(12):7953-9. doi:https://doi.org/10.1128/IAl.73.12.7953-7959.2005.

\section{Figures}

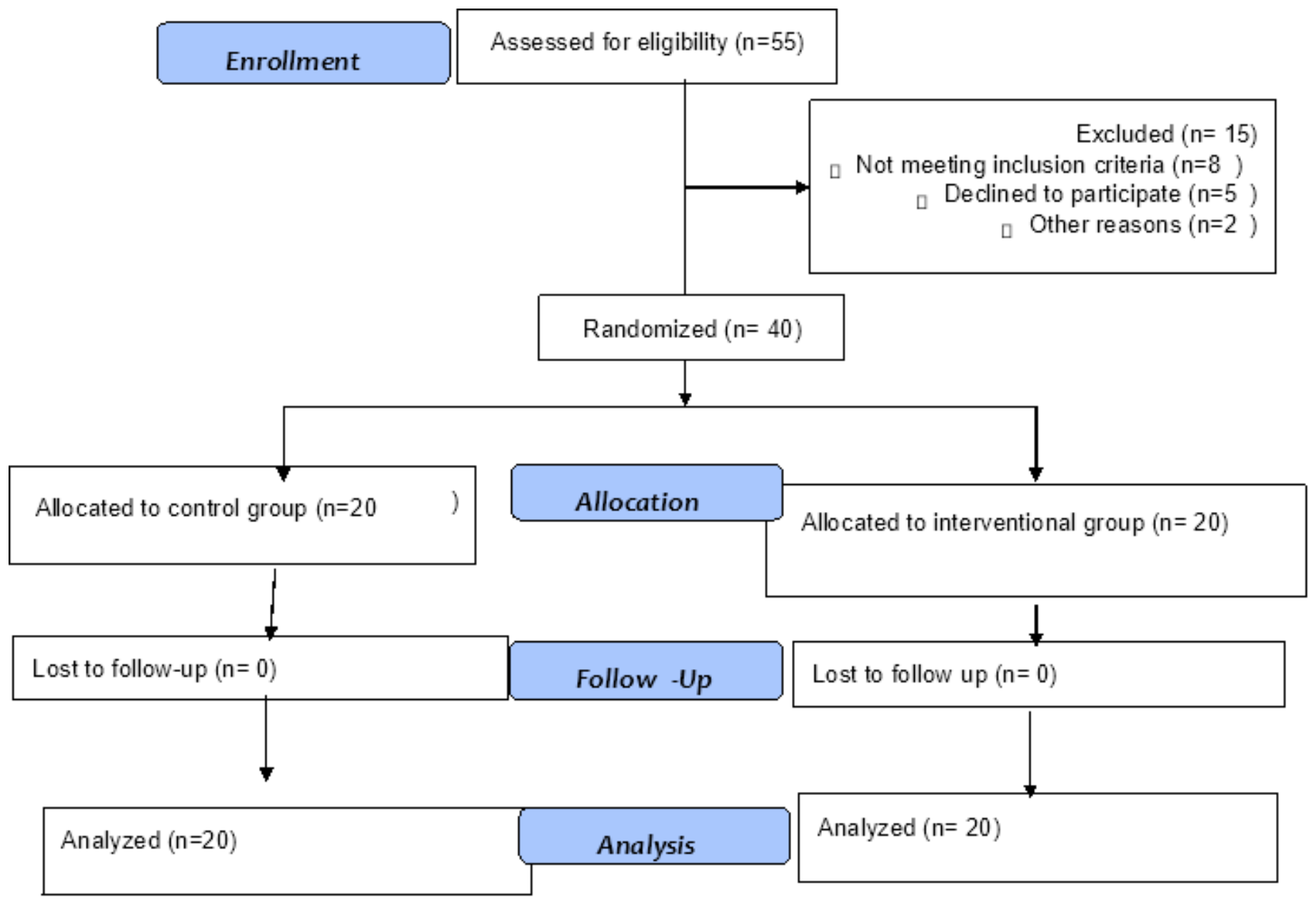

Figure 1

Diagram of the study design 